Review

http://dx.doi.org/10.17784/mtprehabjournal.2014.12.173

\title{
Tests for clinical assessment of the stand-to-sit/ sit-to-stand in subjects post-stroke: a systematic
} review.

\author{
Testes para avaliação clínica do levantar/sentar em cadeira em indivíduos pós-acidente vascular \\ encefálico: revisão sistemática.
}

\author{
Paula Fernanda de Sousa Silva(1), Amanda Ferreira Gusmão(2), Juliane Franco(2), Ludmylla Ferreira

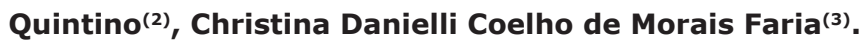 \\ Universidade Federal de Minas Gerais (UFMG), Belo Horizonte (MG), Brazil.
}

\begin{abstract}
Introduction: Individuals with stroke usually show limitations in the performance of daily activities. Among the most limited activities is the stand-up/sit-down, which limitation in performance is a major cause of disability in this population. Objective: The aim of the present study was to describe the clinical tests used to evaluate the stand-up/sit-down in individuals with stroke, considering their protocols and properties. Method: A systematic literature review following the PRISMA (Preferred Reporting Items for Systematic reviews and Meta-Analyses) protocol was performed. Systematic literature searches on the following databases MEDLINE/SCIELO/LILACS/PEDro was performed, using search strategies that included terms referring to tests and individuals with stroke. The inclusion criteria were: use of a clinical test to evaluate the stand-up/sit-down in individuals with stroke and be published in any language until april/2013. Results: Fifteen studies were included, which used the test of three repetitions $(n=1 / 15)$, number of repetitions in $30 s(n=1 / 15)$ and $60 s(n=1 / 15)$, and the five repetitions test $(n=12 / 15)$, for which was investigated reliability with intraclass correlation coefficients (ICC) $(n=2 / 12,0.89 \leq$ ICC $\leq 0.99)$, sensibility/specificity $(n=2 / 12,67 \%-83 \% / 72-75 \%)$ and validity with pearson correlation coefficients $(r)(n=1 / 12,0.75 \leq r \leq 0.83)$. Most part of the studies $(n=8 / 15)$ used chair with seat height fixed and reported the number of repetitions of the test $(n=7 / 15)$, performed with one $(n=3 / 8)$, two $(n=2 / 8)$ or three repetitions $(n=3 / 8)$. Conclusion: The test of five repetitions was used more often in individuals with stroke and the only one for which measurement properties was investigated, which results were adequate. However, standardization of this test considering determining factors for the evaluation of stand-up/sitdown, as chair height and number of repetitions, are still needed.

Key-words: Stroke; Evaluation; Rehabilitation; Movement; Clinical protocols; Review.

\section{Resumo}

Introdução: Indivíduos acometidos pelo acidente vascular encefálico (AVE) comumente apresentam limitações em atividades de sua rotina diária. Dentre as atividades mais comprometidas encontra-se o levantar/sentar em cadeira, cuja limitação é uma das principais causas de incapacidade nessa população. Objetivo: Determinar os testes clínicos que avaliam o levantar/ sentar em cadeira em indivíduos acometidos pelo AVE, considerando seus protocolos e/ou propriedades de medida ou de aplicabilidade investigadas. Método: Trata-se de revisão sistemática da literatura, conforme o protocolo PRISMA (Preferred Reporting Items for Systematic reviews and Meta-Analyses). Foram realizadas pesquisas nas bases de dados MEDLINE/SCIELO/ LILACS/PEDro mediante estratégia de busca composta pela combinação de termos referentes aos testes e aos indivíduos acometidos pelo AVE. Os critérios de inclusão foram: uso de teste clínico que avaliasse o levantar/sentar em cadeira em indivíduos acometidos pelo AVE e publicação em qualquer idioma até abril/2013. Resultados: Foram incluídos 15 estudos que utilizaram os testes de três repetições $(n=1 / 15)$, número de repetições em 30 s $(n=1 / 15)$ e 60 s $(n=1 / 15)$ e teste de cinco repetições $(n=12 / 15)$, para o qual foi investigada confiabilidade por meio de coeficiente de correlação intraclasse $(C C I)(n=2 / 12$, $0,89 \leq \mathrm{CCI} \leq 0,99)$, sensibilidade/especificidade $(n=2 / 12,67 \%-83 \% / 72-75 \%)$ e validade por meio de coeficientes de correlação de Pearson $(r)(n=1 / 12,0,75 \leq r \leq 0,83)$. A maioria dos estudos utilizou cadeira de altura fixa $(n=10 / 15)$ e relatou o número de repetições do teste $(n=8 / 15)$, o qual foi realizado mediante uma $(n=3 / 8)$, duas $(n=2 / 8)$ ou três repetições $(n=3 / 8)$. Conclusão: $O$ teste de cinco repetições foi o mais utilizado em indivíduos acometidos pelo AVE e o único para o qual foram investigadas propriedades de medida, tendo apresentado valores adequados. Contudo, ainda são necessárias padronizações destes testes quanto a fatores determinantes para avaliação do levantar/sentar em cadeira, como altura da cadeira utilizada e número de repetições do teste.
\end{abstract}

Palavras-chave: Acidente Vascular Encefálico; Avaliação; Reabilitação; Movimento; Protocolos clínicos; Revisão.

Received: 27 November 2013. Accepted: 14 March 2014. Published: 30 March 2014.

1. PT; Master student, Post-graduate program in Ciências da Reabilitação, Universidade Federal de Minas Gerais (UFMG), Belo Horizonte (MG), Brazil. 2. Physical Therapy Student and scholarship from CNPq, Universidade Federal de Minas Gerais (UFMG), Belo Horizonte (MG), Brazil.

3. PT, Ph.D. Professor of physical therapy department of Universidade Federal de Minas Gerais (UFMG), Belo Horizonte (MG), Brazil.

Corresponding Author:

Christina Danielli Coelho de Morais Faria. - Departamento de Fisioterapia, Universidade Federal de Minas Gerais.- Av. Antônio Carlos, 6627, CEP 31270-901, Belo Horizonte, Minas Gerais. - Telefone: (0XX31) 3409-4783; Fax: (0XX31) 3409-4781 - E-mail: cdcmf@ufmg.br; chrismoraisf@ yahoo.com 


\section{INTRODUCTION}

In the last four decades there has been an increase of over $100 \%$ in the incidence of stroke in developing countries. ${ }^{(1)}$ Worldwide, the stroke is considered a major cause of chronic disability and specifically in America Latin, the stroke is appointed as the largest public health problem. (2)

Individuals affected by stroke presented dependence in daily activities and social restrictions in all stages post-injury. ${ }^{(3)}$ Among the activities of daily living are more committed to stand up/sit down in the chair, one of the main reasons of disability in these individuals. ${ }^{(4)}$ Therefore, a major goal of the rehabilitation team is to improve the performance of individuals with stroke in carrying out these activities and thus prevent or reduce disabilities in their daily routine, ${ }^{(5)}$ which requires appropriate tools to assess the stand-up /sit down in the chair in the clinical context. ${ }^{(5,6)}$

The first clinical trial to evaluate the proposed stand-up / sit down in the chair was called "timed-stands test" and given the time spent to perform ten repetitions stand-up/sit down on chair. ${ }^{(7)}$ This test was subsequently adapted for versions with fewer repetitions ${ }^{(8)}$ or number of repetitions performed at a given time. ${ }^{(9)}$ The version called "test of five repetitions stand-up/sit down on chair" ("five -repetition sit-to-stand test ") has been the most frequently used and already had adequate reliability results in individuals with cerebral palsy ${ }^{(10)}$ and good clinical applicability in individuals with Alzheimer's disease. ${ }^{(11)}$

The use of clinical trials to evaluate the stand-up/ sit down on chair in different population groups did not show that the products are appropriate for individuals affected by stroke, since specific characteristics of population groups influence the outcomes of tests and properties. ${ }^{(12)}$ Thus, the present study aimed to determine the clinical tests used to assess the stand-up/sit on chair in individuals affected by stroke, considering its protocols and properties.

\section{METHOD}

It is a systematic literature review conducted in accordance with the protocol PRISMA (Preferred Reporting Items for Systematic Reviews and Meta-Analyses), ${ }^{(13)}$ with all steps performed by two independent observers, who at the end of each stage was established consensus between the results obtained. A third examiner was involved in the event of disagreement between the two examiners.

In the first step, electronic searches were conducted on MEDLINE, SciELO, LILACS and PEDro by search strategy given by the combination of terms relating to interest tests and stroke. Subsequently, the studies found were evaluated on the following inclusion criteria: clinical trial use to assess the stand-up/sit down on chair in individuals affected by stroke and have been published in any language to abril/2013. In the second step, the titles were evaluated and in case of the studies was shown that the clearly did not fit the specific inclusion criteria, this was deleted. The same procedure was used in the third step with the analysis of the summary of the studies included in the second stage. In the fourth step, the reading was performed in full of all studies included in the third step and all those who met the inclusion criteria were included. In the fifth stage, active manual search was performed in all references of included studies from the electronic search, following the same procedures.

The sixth step was the discussion between the examiners and definition of five criteria for assessing the methodological quality of included studies, as has been done in other systematic reviews. ${ }^{(14)}$ These criteria were defined based on the major determinants of the activity of raising chair been clearly established ${ }^{(15)}$ and, in the case of no studies that have investigated measurement properties in methodological / statistical recognized as appropriate rules. ${ }^{(12)}$ The criteria were: $\mathrm{C} 1$ : to characterize the study sample (sample size, age, gender, length of stroke, most affected side and a functional description) ${ }^{(6,12)} \mathrm{C} 2$ : describe the test protocol (instruction, familiarization, number of repetitions and speed), C3: Describe positioning of the individual (feet and upper limb) (15) C4: to describe the height of the chair seat used, (15) and C5: deliver results related to testing and/or use appropriate statistical analysis in the case of investigation of measurement properties. ${ }^{(12)}$

Subsequently, for all included studies was independently assigned a score for each of the examiners. If the study would meet certain criteria received one note, and if did not answer, zero. The simple sum of scores of each criterion was used for the final classification of methodological quality: zero for low-quality studies, for two or three moderate quality and four or five to high quality.

\section{RESULTS}

Sixty-nine studies were found in the electronic search, of which 53 were excluded in the second stage of analysis, does not refer to the intended test or poststroke individuals. In the third stage, five studies were excluded for the same previous reasons and, in the fourth step, all eleven studies analyzed are suited to the inclusion criteria and were included. Active manual search was performed in these 11 studies, which resulted in four studies included, distinct from those already found by the electronic search. In total, 15 studies were included in this review. (Figure 1 ).

The majority of studies $(13 / 15,86.6 \%)$ had a score of moderate quality $(5,6,8,17-26)$ and the other with lower quality $(2 / 15,13.4 \%)^{(27,28)}$ (Table 1$)$. Four different test types with varying denominations were found: "Test of 
three repetitions stand-up / sit down on chair" (1/15, $6.7 \%)^{(8)}$ (modified from the "test of five repetitions stand up / sit down on chair"), "test of five repetitions standup / sit down on chair" (11/15, 73.3\%), (5,6,17,18,20-22,24-28) "the number of test repetitions stand-up / sit down on chair in 30 seconds " $(1 / 15,6.7 \%)^{(23)}$ and "test number of repetitions stand-up / sit down on chair 60 seconds " $(1 / 15,6.7 \%)^{(19)}$ (Table 2). The tests were used to refer to functionality, ${ }^{(22,27)}$ muscle strength in lower $\operatorname{limb}^{(17,25)}$ performance from sitting to standing ${ }^{(19)}$ and balance. ${ }^{(6)}$

Most studies $(10 / 15,80 \%)^{(5,6,17-19,21-24,27)}$ utilized sample size greater than 12 individuals, independent ambulating for 10 meters with or without assistive device and mean age between 42 to 59.5

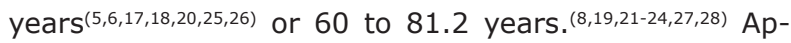
proximately $93.3 \%$ of studies (14/15) described the injury time of the individuals assessed, given as greater than 11 months $^{(5,6,8,17,18,20-28)}$ (Table 2).

Only two studies $(13.3 \%)^{(6,21)}$ describe the complete test protocol (instruction, familiarization, number of repetitions and speed) and none of the studies reported the placement of feet of individuals. Less than half of the

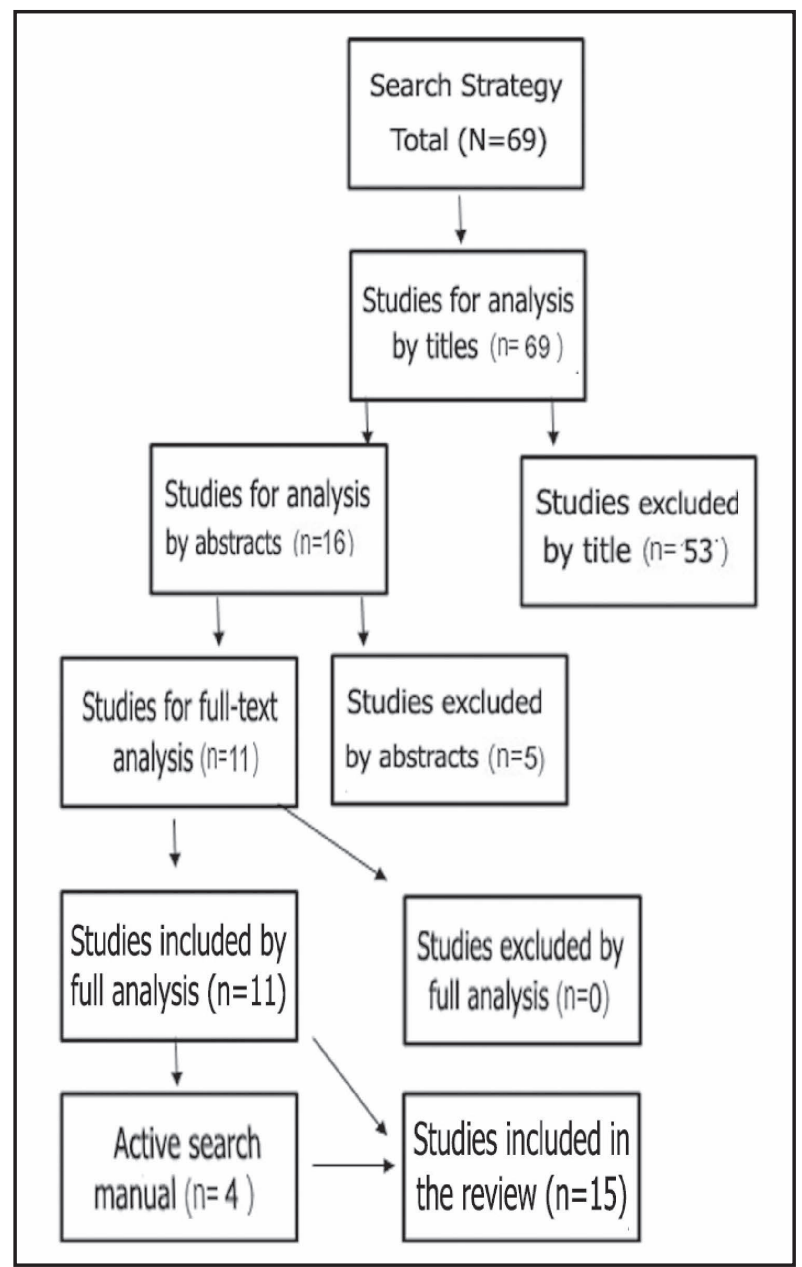

Figure 1. Flowchart of search and selection. Subtitle: $n=$ number of studies. studies described the height of the chair seat used, ${ }^{(5,17-}$ $19,21,23,25,26)$ described by most as fixed $(5,17,18,21,23,25,26)$ and in one study as adjusted to individual leg length. (19) Approximately $66.6 \%(10 / 15)$ of the included studies $^{(5,6,17-19,21,22,24-26)}$ did not allow use of the upper limbs during the test, and of these $40 \%(4 / 10)$ standardized the individual upper limbs crossed chest $\mathrm{t}^{(5,6,18,22)}$ (Table 3 ).

The selected studies, $23 \%(3 / 13)^{(6,18,21)}$ evaluated measurement properties, all for the "test of five repetitions stand-up/sit down on chair". Whereas the names given by the authors, were investigated: test-retest reliability ${ }^{(6,21)}$ inter $^{(21)}$ and intra-rater ${ }^{(21)}$ by the intraclass correlation coefficient (ICC) with values greater than 0.9 and absolute reliability by standard of measurement error and minimal detectable change, with resulting values of 1.8 and 5.0, respectively. ${ }^{(6)}$ Were also investigated to determine sensitivity and specificity cutoff point to discriminate among individuals affected by stroke patients with history of multiple falls, yielding values of $17 s^{(18)}$ and cutoff values for discriminating individuals affected by stroke in elderly healthy, yielding $12.2 \mathrm{~s}$ value. (21) Finally, we investigated the validity of the test for correlation (Pearson correlation coefficient ( $r$ )) with isometric lower limb strength, Berg balance scale and dynamic stability, yielding significant correlations only with the isometric strength of knee(21) (Table 4).

\section{DISCUSSION}

The present study aimed to determine the clinical trials that evaluate the activities stand-up/sit down on chair in individuals affected by stroke, considering its protocols and properties. There was a predominance of studies with moderate quality to low, particularly for non description of the test protocol and the positioning of the individual. (15) Most studies ${ }^{(5,6,17,18,20-22,24-28)}$ used the "test of five repetitions stand-up / sit down on chair", but were also used "test of three repetitions stand-up/ sit down on chair"(8) "test number of repetitions standup / sit down on chair in 30 seconds"(23) and "test number of repetitions stand-up / sit down on chair 60 seconds ".(19) Many of the subjects had functional level from moderate to high and were in the chronic stage post-injury. The reliability properties were investigated ${ }^{(6,21)}$ validity, $^{(21)}$ sensitivity ${ }^{(18,21)}$ and specificity ${ }^{(18,21)}$ only for "test of five repetitions stand-up / sit down on chair", usually with results appropriate.

Most studies that used the "test of five repetitions stand-up / sit down on chair" assessed males, middleaged or elderly between 60 and 70 years. However, considering that much of the prevalence of stroke is observed in individuals over 80 years old and of both gender(29) future studies should include subjects with older age. The subjects assessed in the included studies were also mostly independent ambulating, probably due to the inclusion criteria who selected individuals whose 
Table 1. Assessment of methodological quality of included studies $(n=15)$.

\begin{tabular}{|c|c|c|c|c|c|c|}
\hline Study & C1 & $\mathbf{C 2}$ & C3 & C4 & C5 & Total \\
\hline Wong et al.(26) & 1 & 0 & 0 & 1 & 1 & $3 / 5$ \\
\hline $\mathrm{Ng}$ et al. (25) & 0 & 0 & 0 & 1 & 1 & $2 / 5$ \\
\hline Pardo et al.(6) & 0 & 1 & 0 & 1 & 1 & $3 / 5$ \\
\hline Takatori et al.(23) & 0 & 0 & 0 & 1 & 1 & $2 / 5$ \\
\hline Byl(20) & 1 & 0 & 0 & 0 & 1 & $2 / 5$ \\
\hline Taylor-Piliae et al.(24) & 1 & 0 & 0 & 0 & 1 & $2 / 5$ \\
\hline Boyne et al. ${ }^{(8)}$ & 1 & 0 & 0 & 0 & 1 & $2 / 5$ \\
\hline Mong et al.(21) & 0 & 1 & 0 & 1 & 1 & $3 / 5$ \\
\hline $\mathrm{Ng}^{(5)}$ & 1 & 0 & 0 & 1 & 1 & $3 / 5$ \\
\hline Beninato et al. ${ }^{(18)}$ & 1 & 0 & 0 & 1 & 1 & $3 / 5$ \\
\hline Britton et al. ${ }^{(19)}$ & 1 & 0 & 0 & 1 & 1 & $3 / 5$ \\
\hline LeBrasser et al.(27) & 0 & 0 & 0 & 0 & 1 & $1 / 5$ \\
\hline Belgen et al. ${ }^{(17)}$ & 0 & 0 & 0 & 1 & 1 & $2 / 5$ \\
\hline Ouellette et al.(22) & 1 & 0 & 0 & 0 & 1 & $2 / 5$ \\
\hline Weiss et al.(28) & 0 & 0 & 0 & 0 & 1 & $1 / 5$ \\
\hline
\end{tabular}

Subtitle: $\mathrm{n}$ (number of studies); C1 (first criterion, describe the population - sample size, age, gender, length of stroke, most affected side and a functional description); C2 (second criterion, describing test protocols - education, familiarization, number of repetitions and speed); C3 (third criterion, describe the individual position - feet and lower limbs); C4 (fourth criterion, describing the height of the chair seat used); C5 (fifth criterion, provide the results related to the test - in studies on measurement properties, the statistical analysis was used to correct some property investigated).

Table 2. Characteristics of the population evaluated and tests used in the included studies $(n=15)$.

\begin{tabular}{|c|c|c|c|c|c|c|}
\hline Study & $\mathbf{N}$ & Age (Years) & $\begin{array}{l}\text { Gender } \\
\text { (M/F) }\end{array}$ & Length of Stroke & Functional Description & Test \\
\hline Wong et al. (26) & 35 & $57.26 \pm 7.19$ & $27 / 8$ & More than a year & FM-FM: $26.6 \pm 4.46 / 34$ & "5TSTST $T^{\prime \prime *}$ \\
\hline $\mathrm{Ng}$ et al.(25) & 35 & $57.26 \pm 7.19$ & $27 / 8$ & More than a year & FM-FM: $26.6 \pm 4.46 / 34$ & "5TSTST \\
\hline Pardo et al.(6) & 19 & $53.4 \pm 12.3$ & $9 / 10$ & mean: $45.5 \mathrm{~m}$ & DI & "5TSTST \\
\hline Takatori et al.(23) & 44 & mean: 60 & $32 / 12$ & More than a year & DI & "30-s CST" \\
\hline Byl $\left.\right|^{(20)}$ & 3 & $42-59$ & $1 / 2$ & $15 \mathrm{~m}$ to 10 years & $\mathrm{D}$ and independente on $\mathrm{AC}$ & "5TSTST" \\
\hline Taylor-Piliae et al.(24) & 87 & mean: 70 & $54 / 46$ & $39 \pm 49 \mathrm{~m}$ & $D_{d}(10 \%), D_{l c}(50 \%), D_{n l c}(40 \%)$ & "chair stand test" \\
\hline Boyne et al. ${ }^{(8)}$ & 2 & 68 e 75 & $2 / 0$ & $\cdots \cdots \cdots \cdots$ & FM-FM : $21 / 34$ e $22 / 34$ & "3RSTST" \\
\hline Mong et al.(21) & 12 & $60 \pm 4.8$ & $6 / 6$ & More than a year & DI & "5TSTST" \\
\hline $\mathrm{Ng}^{(5)}$ & 68 & mean: 59.9 & $40 / 28$ & More than a year & DI & "5TSTST" \\
\hline Beninato et al.(18) & 27 & $57.2 \pm 12.4$ & $12 / 15$ & $11 \mathrm{~m}$ or more & DI & "5TSTST \\
\hline Britton et al. ${ }^{(19)}$ & 18 & mean:63-68.4 & $14 / 4$ & $\ldots \ldots \ldots$ & Unable to stand-up/sit down & "STS in 1 minute" \\
\hline LeBrasser et al.(27) & 31 & mean: 66.2 & $23 / 8$ & mean: $17.5 \mathrm{~m}$ & DI & "chair rising"** \\
\hline Belgen et al. ${ }^{(17)}$ & 49 & mean: 59.9 & $31 / 19$ & $62.2 \pm 62.1 \mathrm{~m}$ & $\mathrm{D}(6 \%), \mathrm{D}_{\mathrm{D}}(32 \%), \mathrm{D}_{\mathrm{lc}}(62 \%)$ & "sit to stand" \\
\hline Ouellette et al.(22) & 42 & mean:65.8 -66 & -......... & $31 \mathrm{~m}-2 ., 6$ yeas & DI & "chair-rise" \\
\hline Weiss et al.(28) & 7 & More than 60 & .......... & More than a year & unipodal support $\left.15 \mathrm{~s}_{(\mathrm{MIA}}\right)$ & "chair rise time" \\
\hline
\end{tabular}

Subtitle: $\mathrm{n}$ (number of studies); M (male); F (female); FM-FM (fulg-meyer motor function); 5TSTST (five-times sit-to-stand test); * (refer to the "test of five repetitions stand up / sit down on chair"); m (months); DI (independent ambulator); 30-s CST (30-s chair stand test); D (ambulator); AC (self-care);

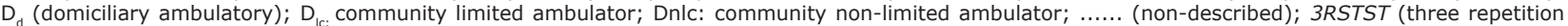
sit-to-stand test); STS (sit to stand); (most affected lower limb)

functional level allowed perform the tests without the assistance of upper limbs, and were in the chronic stage after stroke. This little variability in demographics, stage post-injury and functionality of individuals evaluated restricts the generalizability of the results obtained for certain clinical settings, thus limiting the external validity of the tests used to assess the stand-up / sit down on chair. Studies using the "number of repetitions stand-up / sit down on chair in 30 seconds test"(23) "number of repetitions stand-up / sit down on chair 60 seconds test"(19) and "test of three repetitions of lifting / sit on chair"(8) evaluated individuals mostly males, in the chronic phase after stroke and elderly patients with light to moderate impairment(19) or unable to stand-up / sit down more than three times in 10 seconds. ${ }^{(8)}$ it means, for the older population with stroke were predominantly used data 
Table 3. Chair, positioning of individuals, protocols and results of clinical tests used in the included studies $(n=15)$.

\begin{tabular}{|c|c|c|}
\hline Study & Chair, positioning of individuals and the test protocol. & Test: Mean \pm SD \\
\hline Wong et al. (26) & Chair: altura de 45 cm; MMSS no colo; instruções; MS. & $20.57 \pm 6.95 s$ \\
\hline $\mathrm{Ng}$ et al. (25) & Chair: Height of $45 \mathrm{~cm}$; Upper limbs ${ }_{\mathrm{cp}}$; instruction; test: three rep.; MS. & $20.57 \pm 6.95 s$ \\
\hline Pardo et al. (6) & Chair: fixed height; Upper limbs ${ }_{c t}$; familiarization; test: three rep.; instruction; MS. & $17 \mathrm{~s}$ \\
\hline Takatori et al. (23) & Chair: Height of $43 \mathrm{~cm}$; test: two rep. & $12.3 \pm 4.7 \mathrm{NR}$ \\
\hline Byl (20) & Non described. & $11.4 \mathrm{~s} / 12.4 \mathrm{~s}$ \\
\hline Taylor-Piliae et al. (24) & Test: one rep.; without upper limbs; MS & $19.8 \pm 6.9 \mathrm{~s}$ \\
\hline Boyne et al. ${ }^{(8)}$ & Non described. & $18 \mathrm{~s} / 40$ \\
\hline Mong et al. (21) & Chair: Height of $43 \mathrm{~cm}$; Upper limbs; familiarization; test: three rep.; instruction; MS & $17.1 \mathrm{~s}$ \\
\hline $\mathrm{Ng}{ }^{(5)}$ & Chair: Height of $43 \mathrm{~cm}$; Upper limbs ${ }_{\mathrm{cp}}$; instruction; test: two rep.; MS & $17.9 \mathrm{~s}$ \\
\hline Beninato et al. (18) & Chair: Height of $45 \mathrm{~cm}$; Upper limbs ${ }_{c t}$; instruction; MS & $18.3 \mathrm{~s}$ \\
\hline Britton et al. (19) & Chair: adjustable to individuals lengh leg*; hands ${ }_{c}$; instruction & $9.7 \pm 4.7 \mathrm{NR}$ \\
\hline LeBrasseur et al. (27) & Chair: standars; test: one rep. & $23.6 \mathrm{~s}$ \\
\hline Belgen et al. (17) & Chair: Height of $45 \mathrm{~cm}$; without upper limbs & $17.9 \pm 7.7 \mathrm{~s}$ \\
\hline Ouellette et al. (22) & Upper limbs ${ }_{\mathrm{cp}}$; MS & $23.15 \mathrm{~s}$ \\
\hline Weiss et al. (28) & Chair: fixed seating; test: one rep.; to use upper limbs if necessary & $19.3 \mathrm{~s}$ \\
\hline
\end{tabular}

Table 4. Properties of investigated measures in tests assessing stand-up / sit down in the chair in the studies included. ( $n=3 / 15$ ).

\begin{tabular}{|c|c|}
\hline Study & Test properties \\
\hline Pardo et al. ${ }^{(6)}$ & $\begin{array}{l}\text { Test-retest reliability }(\text { ICC }=0.87) \text { and absolute ( } \text { standard error of measurement }=1.8 \text { and minimal detectable } \\
\text { change }=5.0 \text { ) }\end{array}$ \\
\hline Mong et al. ${ }^{(21)}$ & $\begin{array}{l}\text { Test-retest reliability }(\text { ICC }=0.99) \text {. inter }(\text { ICC }=0.97-0.976) \text { and intra-rater }(\text { ICC }=0.989-0.999) \text {; validity: } \\
\text { isometric strength of the knee flexors of the affected leg }(r=-0.753) \text { and unaffected }(r=-0.830) \text {; sensitivity }= \\
83 \% \text { and specificity }=75 \%\end{array}$ \\
\hline
\end{tabular}

Beninato et al. ${ }^{(18)} \quad$ Sensibility (67\%). Specificity $(72 \%)$. positive probability rate $(2.4)$ and negative $(0.46)$

SUbtitle: $\mathrm{n}$ (number of studies); ICC (intraclass correlation coefficients); $r$ (pearson correlation coefficients)

by time or with less than five repetitions stand-up / sit down on chair tests.

Unlike clinical trials already established,(18) found the tests to evaluate the stand-up / sit down on chair presented protocols that have not been fully defined. Increased speed chair lift, for example, raises the requirement of lower limb muscle guy in this activity. ${ }^{(15)}$ Only $60 \%$ of the studies described the speed given as the highest, probably for maximum biomechanical performance individuals. Much of the included studies provided instructions to all patients, but variations were found. $(5,6,18,19,21,25,26,28)$ Regarding familiarity, only two studies have reported that adopted this procedure ${ }^{(6,21)}$ Non standardization of instructions and skipping familiarization impairs performance on the test and the individual may have influenced the results. ${ }^{(16)}$

There are no studies which report the ideal number of repetitions of these clinical tests, probably for this reason, the number of repetitions described in most studies varied from one to three replications. However, in a study of individuals affected by stroke evaluated by other clinical tests as appropriate gait speed, reliability and similar values were obtained with a repetition, average two-and three replications and the best / worst measure of three repetitions, suggesting that performing a repeat would be enough to obtain reliable measures. (30) Thus, it is recommended that future studies determine the ideal number of repetitions of tests that assess the stand-up / sit down on chair in individuals post-stroke considering the outcomes of the test and its measurement properties, therefore this population the possibility of performing fewer repetitions of the test increases its applicability. ${ }^{(30)}$

Another key feature for to the lift chair is the seat height in relation to the individual leg length, which can make it more or less challenging activity. ${ }^{(15)}$ Most of the included studies did not describe this feature, which complicates the interpretation and compare the results $^{(15)}$ and replication of the tests. ${ }^{(16)}$ For studies that described the chair height, most used was fixed height $(5,6,17,18,21,23,25-27)$ and only one study used adjustable height. ${ }^{(8)}$ It is recommended to conduct studies to 
evaluate whether there are differences in the results of different tests that assess the stand-up/sit down on chair considering different seat heights.

Failure to use the upper limbs during lift chair, in turn, increases the demand for biomechanics achievement in this activity ${ }^{(15)}$ and possibly for this reason, the majority of studies did not allow the use of the upper limb test by positioning individuals mostly with upper limbs crossed over the chest $(50 \%)$ or in front of the body $(10 \%)$, which indicates that the positioning of the upper limbs is possible in this population. Moreover, the positioning of the feet of individuals (one in front of another, ${ }^{(4)}$ parallel or both front / behind the knees) ${ }^{(15)}$ is also a determinant for the activity of raising chair, may modify the demand biomechanics and this activity strategy. ${ }^{(15)}$ However, this factor was not described in any of the studies found, limiting the interpretation of results and replication of the tests used.

No studies that best reported test to evaluate the stand-up/ sit down considering the outcomes of interest in the population with stroke were found. However, one study found modified the "five repetitions standup/sit down on chair test" for "three repetitions standup/sit down on chair test" after checking that individuals were not able to perform five repetitions of stand-up/sit down. ${ }^{(8)}$ However, in a elderly study, ${ }^{(5)}$ it was found that the majority reached the maximum peak power of lower limbs after fifth iteration of stand-up /sit down in about 20 seconds. Since the average time the "five repetitions stand-up/sit down on chair test" in individuals affected by stroke can reach 20 seconds or more, ${ }^{(18,22,27,28)}$ tests with more than five repetitions and the number of data repetitions in 30 seconds and 60 seconds could learn more about the biomechanics demand for lower limbs, although they may compromise the applicability of the test due to the low fatigue threshold commonly present in that population. ${ }^{(3)}$ Thus, future studies should determine how many repetitions of the stand-up / sit down in the chair are required for lower limb submit their peak wattage without compromising the applicability of the test in individuals affected by stroke.

The tests used to evaluate the stand-up / sit down on chair were adopted to refer to different outcomes (functionality, ${ }^{(17,24)}$ lower limb strength ${ }^{(6,20,25)}$ balance) $)^{(5)}$, but none have been validated for all them in affected individuals post-stroke. Measurement properties were investigated only for "five repetitions stand-up / sit down on chair test". This test showed good test-retest reliability ${ }^{(6,21)}$ intrarater ${ }^{(21)}$ and inter-examiner, ${ }^{(21)}$ and all studies evaluating this property used ICC, indicating correlation and concordance between measures and considers the sample variance in its calculation, being the most suitable and recommended for investigation of the reliability of numerical variables, ${ }^{(6)}$ as are the outcomes of clinical tests used, which gives good statistical quality studies. One of the studies that investigated reliability ${ }^{(6)}$ used, and ICC standard size and minimum detectable change error values relate to the measurement of the response stability over time. Standard error of measurement reflects the estimated standard error of a set of repeated measures and minimal detectable change reflects how much of the change in the values obtained at two different time points are due to real change and not a bug.(12) These values reflect the variability of the data and thus add value to the information CCI results. ${ }^{(12)}$

The validity of the test was investigated by a study which did not specify the type of validity investigated: the outcome of the test was correlated with isometric strength of the lower limbs (knee, hip and ankle) and balance. Only correlations with the extensor muscles of both knees were significant, negative and good magnitude, possibly due to population evaluated had lower motor and balance impairments. In this population, so the best test performance (shorter) the greater the force of the knee extensors bilaterally. However, given the diversity of levels of impairment in individuals affected by stroke, ${ }^{(5,6)}$ still further investigations on the validity of the "test of five repetitions stand-up / sit down on chair" in this population are needed.

The test also showed greater sensitivity to discriminate elderly individuals affected by stroke than specificity for discriminating elderly post stroke individuals at a cut off of 12.2 seconds $^{(21)}$ and greater sensitivity to discriminate individuals affected by stroke who presented stories multiple drops from individuals without these events, cut off of 17 seconds. ${ }^{(18)}$ This second cut off (17 seconds) was greater than the first (12 seconds) probably because falls are present in most affected individuals and with time larger test.

\section{CONCLUSION}

Clinical evaluation activities of stand-up/ sit down on chair in individuals affected by stroke have been carried out using four different tests, and the "test of five repetitions stand-up / sit down on chair" the most widely used version and which has been investigated some property measurement, usually with appropriate for reliability, validity, sensitivity and specificity results. There are few data to allow standardization of the testing protocols used, because the influence of the determining factors for the performance of stand-up / sit down in the chair was not clearly established for the tests. No individuals were evaluated in the acute or subacute phase of stroke and / or with more impaired motor function . Therefore, there is still important to be informed about the use of clinical trials that evaluate the activities up / sit on chair in post-stroke individuals so that they can be appropriately adopted in clinical practice issues. 


\section{REFERENCES}

1. Feigin VL. Stroke in developing countries: can the epidemic be stopped and outcomes improved?. Lancet Neurol. 2007;6(2):94-7.

2. Johnston SC, Mendis S, Mathers CD. Global variation in stroke burden and mortality: estimates from monitoring, surveillance, and modelling. Lancet Neurol. 2009;8(4):345-54.

3. Karatas M, Çetin N, Bayramoglu M, Dilek A. Trunk muscle strength in relation to balance and functional disability in unihemispheric stroke patients. Am J Phys Med Rehabil. 2004;83(2):81-7.

4. Roy G, Nadeau S, Gravel D, Malouin F, McFadyen BJ, Piotte F. The effect of foot placement and chair height on the asymmetry of vertical forces during sit-to-stand and stand-to-sit tasks in individuals with hemiparesis. Clin Biomech. 2006;21:585-93.

5. Ng SSM. Balance ability, not muscle strength and exercise endurance, determines the performance of hemiparetic subjects on the timed-sit-to-stand test. Am J Phys Med Rehabil. 2010;89(6):497-504.

6. Pardo V, Knuth D, McDermott B, Powell J, Goldberg A. Validity, reliability and minimum detectable change of the maximum step length test in people with stroke. J Neurol Sci. 2013;15;325(1-2):74-8

7. Czuka M, McCarty DJ. Simple method for measurement of lower extremity muscle strenght. Am J Med. $1985 ; 78(1): 77-81$.

8. Boyne P, Israel S, Dunning K. Speed-dependent body weight supported sit-to-stand training in chronic stroke: a case series. J Neurol Phys Ther. 2011;35(4):178-84.

9. Blankevoort CG, Heuvelen MJG, Scherder EJA. Reliability of six physical performance tests in older people with dementia. Phys Ther. 2012;93(1):69-78.

10. Wang TH, Liao HF, Peng YC. Reliability and validity of the five-repetition sit-to-stand test for children with cerebral palsy. Clin Rehabil. 2011;26(7):664-71.

11. Suttanon P, Hill KD, Dodd KJ, Said CM. Retest reliability of balance and mobility measurements in people with mild to moderate Alzheimer's disease. Int Psychogeriatr. 2011;23(7):1152-9.

12. Portney LG, Watkins MP. Foundations of clinical research: applications to practice. $3^{a}$ ed. New Jersey: Prentice Hall. 2009.

13. Moher D, Liberati A, Tetzlaff J, Altman DG. Preferred reporting items for systematic reviews and meta-analyses: the PRISMA statement. PLoS Med. 2009;339:332-6.

14. Bohannon RW. Test-retest reliability of the five-repetition sit-to-stand test: a systematic review of the literature involving adults. J Strength Cond Res. 2011;25(11):3205-7.

15. Janssen WGM, Bussmann HBJ, Stam HJ. Determinants of sit-to-stand movement: a review. Phys Ther. 2002;82(9):866-79.

16. Nascimento LR, Caetano LCG, Freitas DCMA, Morais TM, Polese JC, Teixeira-Salmela LF. Diferentes instruções durante teste de velocidade de marcha determinam aumento significativo na velocidade máxima de indivíduos com hemiparesia crônica. Rev Bras Fisioter. 2012;16(2):1-6.

17. Belgen B, Beninato M, Sullivan PE, Narielwalla K. The association of balance capacity and falls self-efficacy with history of falling in community-dwelling people with chronic stroke. Arch Phys Med Rehabil. 2006;87(4):554-61.

18. Beninato M, Portney LG, Sullivan PE. Using the International Classification of Functioning, Disability and Health as a framework to examine the association between falls and clinical assessment tools in people with stroke. Phys Ther. 2009;89(8):816-28.

19. Britton E, Harris N, Turton A. An exploratory randomized controlled trial of assisted practice for improving sit-tostand in stroke patients in the hospital setting. Clin Rehabil. 2008;22(5):458-68.

20. Byl NN. Mobility training using a bionic knee orthosis in patients in a post-stroke chronic state: a case series. J Med Case Rep. 2012;6(216):1-5.

21. Mong Y, Teo TW, Ng SS. 5-repetition sit-to-stand in subjects with chronic stoke: reliability and validity. Arch Phys Med Rehabil. 2010; 91(3):407-13.

22. Ouellette MM, LeBrasseur NK, Bean JF, Phillips E, Stein J, Frontera W, et al. High-intensity resistance training improves muscle strength, self-reported function, and disability in long-term stroke survivors. Stroke. 2004;35(6):1404-9.

23. Takatori K, Matsumoto D, Okada Y, Nakamura J, Shomoto K. Effect of intensive rehabilitation on physical function and arterial function in community-dwelling chronic stroke survivors. Top Stroke Rehabil. 2012;19(5):377-83.

24. Taylor-Piliae RE, Latt LD, Hepworth JT, Coull BM. Predictors of gait velocity among community-dwelling stroke survivors. Gait Posture. 2012;35(3):395-9. 
25. Ng SS, Ng HH, Chan KM, Lai JC, To AK, Yeung CW. Reliability of the 12-step ascend and descend test and its correlation with motor function in people with chronic stroke. J Rehabil Med. 2013;45(2):123-9.

26. Wong SST, Yam MS, Ng SSM. The figure-of-eight walk test: reliability and associations with stroke-specific impairments. Disabil Rehabil. 2013;35(22):1896-902.

27. LeBrasseur NK, Sayers SP, Ouellette MM, Fielding RA. Muscle impairments and behavioral factors mediate functional limitations and disability following stroke. Phys Ther. 2006;86(10):1342-50.

28. Weiss A, Toshimi S, Bean J, Fielding R. High intensity strength training improves strength and functional performance after stroke. Am J Phys Med Rehabil. 2000;79(4):369-76.

29. Roger VL, Go AS, Lloyde-Jones DM, Benjamin EJ, Borden WB, Bravata DM, et al. Heart disease and stroke statistics - 2012 update: a report from the American Heart Associantion. Circulation. 2012;125(1):188-97.

30. Faria CDCM, Teixeira-Salmela LF, Neto MG, Rodrigues-de-Paula F. Performance-based tests in subjects with stroke: outcome scores, reliability and measurement errors. Clin Rehabil. 2012;26(5):460-9. 